\title{
Damage estimation on concrete gravity dams through artificial accelerograms
}

\author{
Enrico Zacchei ${ }^{1, *}$, José Luis Molina ${ }^{1}$ \\ ${ }^{1}$ Higher Polytechnic School of Ávila, University of Salamanca (USAL), 50 Hornos Caleros Avenue, \\ 05003, Ávila, Salamanca, Spain
}

\begin{abstract}
The aim of this paper is to analyse the damage on gravity dams through artificial earthquakes from two methods. The first procedure defines the performance and the response curve of concrete gravity dams using a harmonic function which establishes linear displacements. The other procedure to obtain the artificial earthquake defines the power spectral density function consistent with the response spectrum. This artificial accelerogram is necessary to quantify the response curve of concrete gravity dams in the time domain. The seismic activity in Spain is not frequent, therefore it is often difficult to select real accelerograms to perform a complete seismic analysis, which makes artificial accelerograms extremely useful. Finally, combining these two procedures, a damage index is determined for assessing the crack's magnitude. These both efficient and practical procedures are useful to develop further complicated analysis.
\end{abstract}

\section{Introduction}

This paper describes two different methodologies, one defines the artificial accelerations under a novel analytical model of Power Spectral Density (PSD) function; the other one estimates the damage on concrete gravity dams. The main advantages of the first methodology may comprise its good applicability and compatibility with different spectra. Furthermore, the properties of the artificial accelerograms can be modified depending on the analysis to be carried out. Unfortunately, the artificial accelerograms do not account the seismological and geotechnical context.

On the other hand, the main advantage of the second method is that it is not necessary a nonlinear model to define the material behaviour.

Except for few regions in the world where a set of earthquake records are available, artificial accelerograms are used to carry out the time-history analysis. Some applications are shown in literature, for example for artificial accelerograms generated via wavelet transform changing the frequency content $[1,2]$.

Earthquake damage assessments can be difficult to carry out given that, during the earthquake shaking, the frequency and the amplitude of the seism change with the stiffness reduction. The definition of the dynamic stiffness is difficult to be asserted because the material behaviour is related to complex aspects to be defined. In literature there are some

\footnotetext{
*Corresponding author: enricozacchei@usal.es
} 
studies to calculate the nonlinear parameters based on the plastic damage model and residual seismic bearing capacity for dams [3] or based on ductility and hysteretic energy for structure [4].

In this paper, in order to implement both methodologies, an ideal concrete gravity dam has been studied. A damage index through the artificial acceleration is estimated from an ad hoc generated stochastic process model.

\section{Artificial accelerograms}

The artificial accelerations coherent with the elastic spectrum has been calculated by using the PSD function defined by [5] and developed in [6].

The definition of the artificial accelerograms has been carried out by using a methodology that is well applicable to the Spanish elastic spectrum with three branches defined in Spanish code [7].

The accelerations $\mathrm{a}(\mathrm{t})$ in the time-domain $\mathrm{t}$ are calculated with the model defined in the literature [8]:

$$
a(t)=I(t) \sum_{i=1}^{n} A_{i} \sin \left(\omega_{i} t+\phi_{i}\right) \approx I(t) \sum_{i=1}^{n} \sqrt{2 P S D\left(\omega_{i}\right) \Delta \omega_{i}} \sin \left(\omega_{i} t+\phi_{i}\right)
$$

Equation 1 is formed by three parts, i.e. the modulation function $I(t)$, the amplitude of the accelerogram $A_{i}$ obtained from literature [5] and the sinusoidal function with a circular frequency $\omega_{\mathrm{i}}$ and a phase angle $\phi_{\mathrm{i}}$. The modulation function simulates the stationary and transitory condition of a real earthquake and it has a trapezoidal shape [6]. The sinusoidal function represents the sum of a series of simple harmonic components $n$, which define the vibrations of the accelerogram.

The methodology is explained as it follows. Firstly, an elastic spectrum $S_{e}(T)$ is chosen and is defined by following parameters: structural periods $T_{A}$ and $T_{B}$, soil coefficient $C$, contribution coefficient $\mathrm{K}$ and Peak Ground Acceleration (PGA). The viscous damping ratio and the dynamic amplification factor are assumed $5 \%$ and 2.5 , respectively. The elastic spectrum is defined by:

$$
S_{e}(T)=\left\{\begin{array}{c}
P G A\left(1+1.5 \frac{T}{T_{A}}\right), \text { for } T<T_{A} \\
2.5 P G A, \text { for } T_{A} \leq T \leq T_{B} \\
P G A\left(K \frac{C}{T}\right), \text { for } T>T_{B}
\end{array}\right.
$$

$\mathrm{K}$ should account the influence of different types of expected earthquakes and in the Spanish code [7] ranges 1.0-1.3. However, given the complexity at defining the seismic acceleration, the authors believe that $\mathrm{K}$ has no meaning and it cannot be defined for a simple coefficient.

Then PSD function in frequency-domain $\omega$ is calculated as follows:

$$
P S D(\omega)=\left\{\begin{array}{l}
P S D_{0}\left(\frac{\omega}{\omega_{B}}\right)^{e_{1}}, \text { for } 0<\omega \leq \omega_{B} \\
P S D_{0}\left(\frac{\omega}{\omega_{B}}\right)^{e_{2}}, \text { for } \omega_{B}<\omega \leq \omega_{A} \\
P S D_{0}\left(\frac{\omega_{A}}{\omega_{B}}\right)^{e_{2}}\left(\frac{\omega}{\omega_{A}}\right)^{e_{3}}, \text { for } \omega>\omega_{A}
\end{array}\right.
$$

where $\omega_{\mathrm{A}}$ and $\omega_{\mathrm{B}}$ are the circular frequencies of the structure related to the $\mathrm{T}_{\mathrm{A}}$ and $\mathrm{T}_{\mathrm{B}}$, respectively and $e_{1}, e_{2}$ and $e_{3}$ are coefficients that mainly depend on $\omega$, viscous damping ratio and dynamic amplification factor. $\mathrm{PSD}_{0}$ represents the peak value of the PSD function. 
Once $I(t)$ and $A_{i}$ are defined, finally, the artificial accelerogram a(t) by Eq. 1 is computed. The obtained maximum acceleration is $0.924 \mathrm{~g}$, which is inconsistent with the PGA $=0.34 \mathrm{~g}$ because the calculation is stochastic. In order to solve this inconsistence, Acceleration Scale Factors (ASF) have been introduced. The accelerations have been scaled of $0.924 / 0.34=2.72$ and $2.72 / 2=1.36$, therefore, the used accelerations are $\mathrm{a}_{1}(\mathrm{t}), \mathrm{a}_{2}(\mathrm{t})$ and $\mathrm{a}_{3}(\mathrm{t})$ with the maximum acceleration $0.924 \mathrm{~g}, 0.68 \mathrm{~g}$ and $0.34 \mathrm{~g}$, respectively. Thus, the dam is analysed under the action of the same earthquake with different amplitudes.

Figure 1 shows the results and Table 1 shows the parameters that have been used in the analysis.
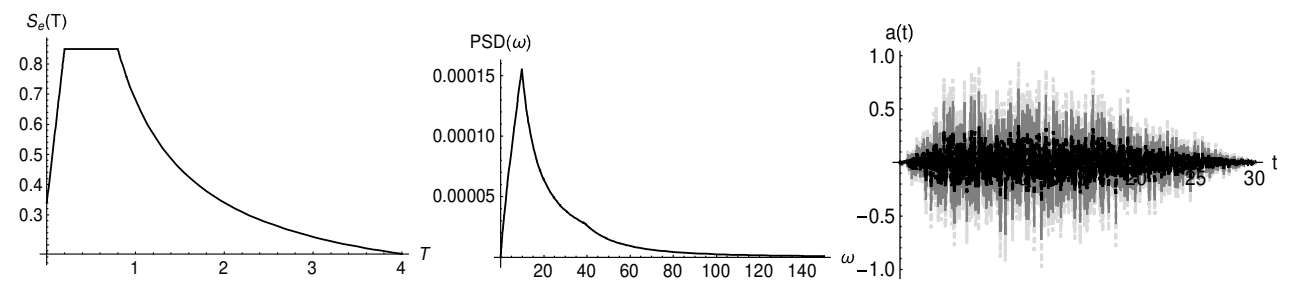

Fig. 1. Elastic spectrum (left), PSD function (middle) and three artificial accelerograms (right) $a_{1}(t)$ (dashed light grey), $\mathrm{a}_{2}(\mathrm{t})$ (solid grey) and $\mathrm{a}_{3}(\mathrm{t})$ (dashed black) developed by software [9].

Table 1. Data of the analysis.

\begin{tabular}{lcccccc}
\hline \multirow{2}{*}{ PSD function } & PSD $_{\mathbf{0}}\left(\mathbf{g}^{2} /(\mathbf{r a d} / \mathbf{s})\right)$ & $\boldsymbol{\omega}_{\mathbf{A}}(\mathbf{r a d} / \mathbf{s})$ & $\boldsymbol{\omega}_{\mathbf{B}}(\mathbf{r a d} / \mathbf{s})$ & $\mathbf{e}_{\mathbf{1}}$ & $\mathbf{e}_{2}$ & $\mathbf{e}_{\mathbf{3}}$ \\
& $1.554 \times 10^{-4}$ & 39.269 & 9.817 & 0.826 & -1.247 & -2.592 \\
\hline Elastic & $\mathbf{P G A}(\mathbf{g})$ & $\mathbf{S}_{\mathbf{e}}(\mathbf{T})_{\max }$ & $\mathbf{T}_{\mathbf{A}}(\mathbf{s})$ & $\mathbf{T}_{\mathbf{B}}(\mathbf{s})$ & $\mathbf{K}$ & $\mathbf{C}$ \\
spectrum & 0.34 & $0.85 \mathrm{~g}$ & 0.16 & 0.64 & 1.0 & 2.0 \\
\hline Artificial & $\mathbf{I}(\mathbf{t})$ & $\phi_{\mathbf{i}}$ & $\mathbf{n}$ & & & \\
accelerogram & $0-4 \mathrm{~s} ; 4-15 \mathrm{~s} ; 15-30 \mathrm{~s}^{*}$ & $0<\phi_{\mathrm{i}}<2 \pi$ & 1500 & & & \\
\hline
\end{tabular}

*Intervals of the three branches of the I(t) shape.

The results for the artificial accelerograms are satisfactory. However, despite the accelerations referred to the elastic spectrum present in the Spanish code [7], the accelerograms do not account the characteristic of an earthquake, e.g. energy content and relation between the magnitude and distance of events.

Other inconvenient is that this methodology is stationary in time, in terms of the amplitude of motion but real accelerograms are often more irregular. However, in structural engineering the maximum values are of interest therefore the method is efficacious.

\section{Results: damage estimation on dams}

The earthquake damage estimation for concrete gravity dams is based on the methodology proposed in the literature [10]. The methodology defines the performance and response curve of the structure. The procedures have been explained below but for more details the reader may refer to relative literature [10].

In this analysis the central block of an ideal concrete gravity dam has been studied. The volume value is coherent with the mean volume value of the concrete gravity dam placed in Spain. These data are available in database $[11,12]$.

Table 2 shows the data of the structure with the stiffness that is calculated by: $4 \pi^{2} \mathrm{Mass} / \mathrm{T}_{1}^{2}$.

From database [11,12], for concrete gravity dams with high $>61.0 \mathrm{~m}$, the mean height and the mean base are $86.35 \mathrm{~m}$ and $67.55 \mathrm{~m}$, respectively. The ratio is $86.35 / 67.55=1.28$. 
Consistently with a considered ideal volume of $2400.0 \mathrm{~m}^{3}$, the dam could have a height of $78.0 \mathrm{~m}$ and a base of $61.0 \mathrm{~m}$.

Table 2. Data of the central block of the concrete gravity dam.

\begin{tabular}{ccccc}
\hline Volume $\left(\mathbf{m}^{\mathbf{3}}\right)$ & Density of concrete $\left(\mathbf{K N} / \mathbf{m}^{\mathbf{3}}\right)$ & Mass $(\mathbf{k g})$ & $\mathbf{T}_{\mathbf{1}}(\mathbf{s})$ & Stiffness $(\mathbf{N} / \mathbf{m})$ \\
\hline 2400.0 & 24.0 & $5760.0 \times 10^{3}$ & 0.35 & $1858.22 \times 10^{6}$ \\
\hline
\end{tabular}

The trigonometric function in the time-domain $t$ to define the Cumulative Inelastic Area (CIA) of the performance curve is:

$$
C D H=\frac{C_{u}}{C_{y}} \sin \frac{2 \pi t}{T_{1}}
$$

where $T_{1}$ is the structure's fundamental period, $C_{u}$ and $C_{y}$ are the ultimate and yielding crest displacement capacities, respectively.

The procedure to define the response curve is divided into: (i) estimation of $\mathrm{C}_{\mathrm{u}}$ and $\mathrm{C}_{\mathrm{y}}$; (ii) definition of $\mathrm{T}_{1}$; (iii) quantification of the number of Demand Capacity Ratio (DCR) to carry out the analysis step-by-step; (iv) calculation of the CIA of the performance curve; (v) drawing of the performance curves. The area is between $\left(\mathrm{C}_{\mathrm{u}} / \mathrm{C}_{\mathrm{y}}\right)_{\mathrm{i}}$ of step $\mathrm{i}$ and $\left(\mathrm{C}_{\mathrm{u}} / \mathrm{C}_{\mathrm{y}}\right)_{\max }$. In this analysis seven points $(i=7)$ have been used.

To define the response curve the process is similar to the employed process to calculate performance curve. However, it is not the same because, due to the great irregularity of the earthquake accelerations, CIA is complicated to calculate. The following approximated equation has been used by authors to solve this inconvenient: CIA $=n_{p}(2 \times 0.05) /(2 \times 3)=$ $0.1\left(\mathrm{n}_{\mathrm{p}} / 6\right)$.

The procedure to define the performance curve is: (i) defining the $\mathrm{C}_{\mathrm{y}}$; (ii) individualizing the sum of the elastic displacement peaks $n_{p}$ that exceed $C_{y i}$; (iii) multiplying $n_{p}$ by two times the step time of $0.05 \mathrm{~s}$.

To eliminate the descending branches of the time-history and to consider only the positive peak times, a division by two and three, respectively, has been made. The displacement is between $\mathrm{C}_{\mathrm{yi}}$ of step $\mathrm{i}$ and $\mathrm{C}_{\mathrm{y} \text {,max. }}$. Seven points $(\mathrm{i}=7$ ) have been used. DCR is between 1.0 and the maximum elastic displacement divided by $\mathrm{C}_{\mathrm{y}}$. Figure 2 shows the elastic displacements used to obtain the response curve and the sinusoidal function $\mathrm{CDH}$ defined by Eq. 4 to obtain the performance curve.
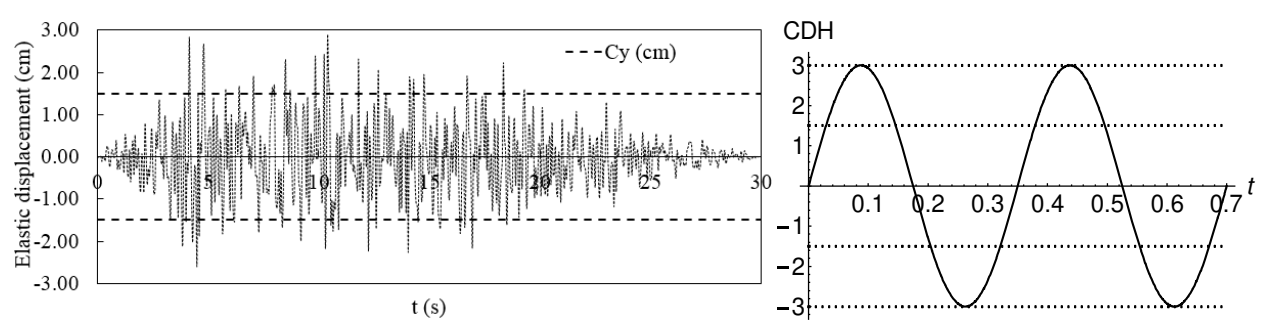

Fig. 2. $\mathrm{CDH}$ function (right) and linear elastic displacement (left) in the t-domain of the dam for $\mathrm{C}_{\mathrm{u}} / \mathrm{C}_{\mathrm{y}}=3, \mathrm{C}_{\mathrm{y}}=1.5 \mathrm{~cm}$ and $\mathrm{T}_{1}=0.35 \mathrm{~s}$.

$C_{y}$ is fixed, whereas $C_{u} / C_{y}$ ratio change. Considering $C_{y}=1.5 \mathrm{~cm}$, the $C_{u}$ ranges 2.25 to $6.0 \mathrm{~cm}$. Figure 3 shows the results of the analysis through the response curves (solid and dashed lines) and response curves (dotted lines) for CIA vs. DCR.

The Damage Index (DI) is defined by: $\min \left\{1, A_{r} / A_{p}\right\}$, where $A_{p}$ is the area under the performance curve (the central dotted lines in the graphics in Figure 3 ) and $A_{r}$ is the area under the response curve. For DI $<0.5$ the dam suffers minor damage, for $0.5<\mathrm{DI}<1.0$ the 
dam damage is moderate and for DI $=1.0$ the dam is subject to severe damage. Table 3 shows the DI obtained in the analysis. For $\mathrm{a}_{3}(\mathrm{t})$ the dam central block does not suffer damage because the accelerations are too low to excite the rigid structure.

Table 3. DI obtained in the analysis for $\mathrm{C}_{\mathrm{u}} / \mathrm{C}_{\mathrm{y}}$ and for both $\mathrm{a}_{1}(\mathrm{t})$ and $\mathrm{a}_{2}(\mathrm{t})$.

\begin{tabular}{|c|c|c|c|c|c|}
\hline \multirow[b]{2}{*}{$\mathbf{C}_{\mathrm{u}} / \mathbf{C}_{\mathbf{y}}$} & \multicolumn{2}{|c|}{ DI } & \multirow[b]{2}{*}{$\mathbf{C}_{\mathrm{u}} / \mathbf{C}_{\mathbf{y}}$} & \multicolumn{2}{|c|}{ DI } \\
\hline & $\mathbf{a}_{1}(\mathbf{t})$ & $\mathbf{a}_{2}(\mathbf{t})$ & & $\mathbf{a}_{1}(\mathbf{t})$ & $\mathbf{a}_{2}(\mathbf{t})$ \\
\hline 1.5 & 0.767 & 0.360 & 3.0 & 0.366 & 0.172 \\
\hline 2.0 & 0.560 & 0.263 & 3.5 & 0.312 & 0.147 \\
\hline 2.5 & 0.442 & 0.207 & 4.0 & 0.273 & 0.128 \\
\hline
\end{tabular}

Damages usually occur in the base and in the crown of the dam, and in the points where the slope changes. For severe damage, the cracks propagate along the whole upstream and downstream face.
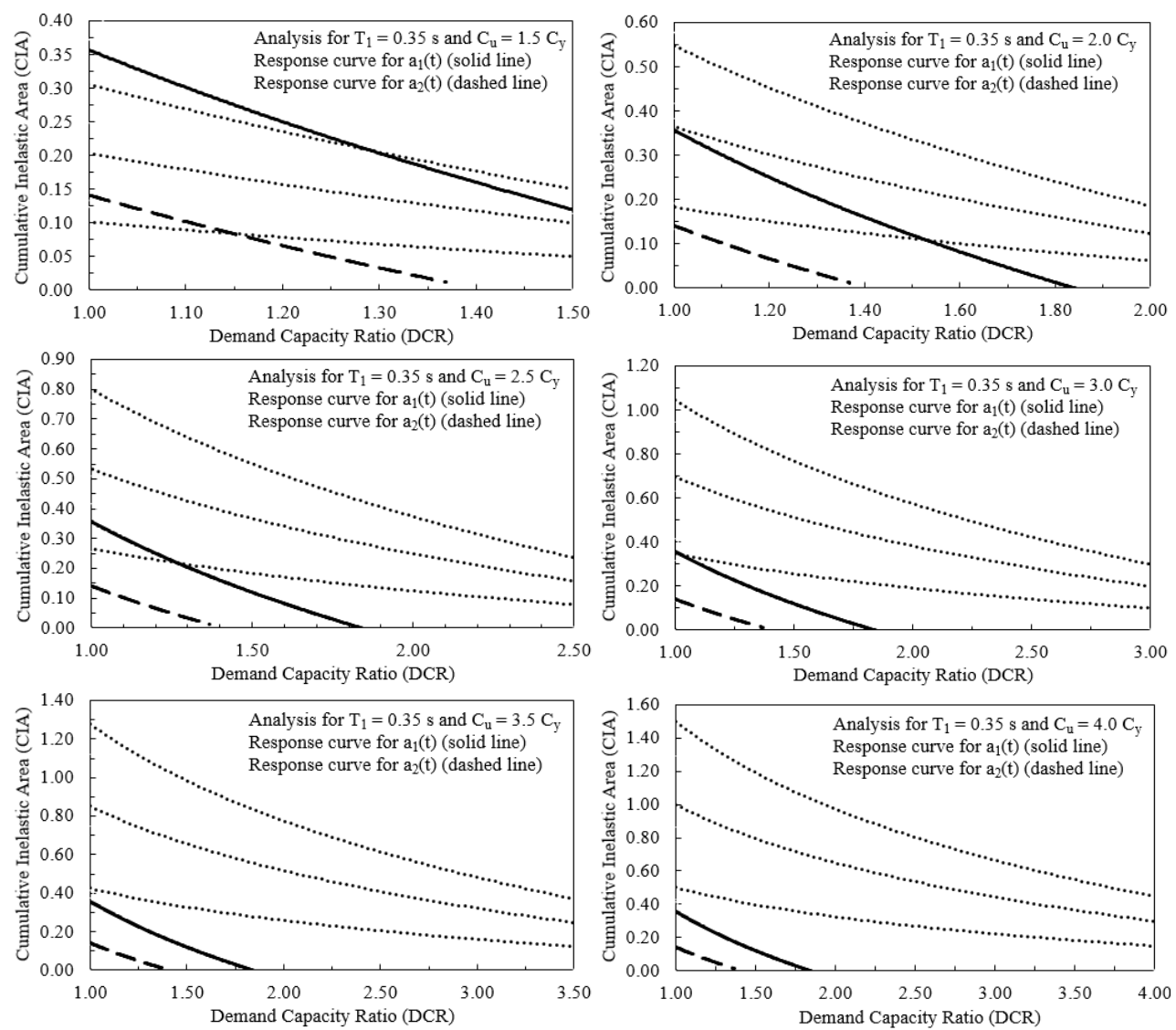

Fig. 3. Results of the analysis of the dam's central block.

\section{Conclusions}

This paper describes two methodologies related to the definition of artificial acceleration by using the model of PSD function and to the estimation of the damage of concrete gravity dams. 
Artificial accelerograms are consistent with Spanish elastic spectrum.

Because the first vibration mode of the gravity dams is predominant, the damage analysis is based on the fact that the cumulative inelastic area can be assumed as a harmonic crest displacement time-history. Under this hypothesis it is possible to develop the damages by using $\mathrm{CDH}$ function.

An ideal concrete gravity dam, has been studied to estimate the damage index under three artificial accelerograms.

The obtained maximum acceleration is $0.924 \mathrm{~g}$. The obtained DI ranges from 0 to 0.767 , i.e. when the dam is intact and when it is moderately damaged, respectively.

This paper emphasizes the importance of selecting individual parameters of artificial accelerogram which affect the seismic response of structures.

The authors are developing these theories and tools aimed to improve their use. Future research is planned to be published and patented.

The first author acknowledges the "Servicios Informáticos CPD" of the University of Salamanca for the Wolfram Mathematica license and the University of Salamanca to pay the rights (when applicable) to completely download all the references.

\section{References}

[1] D. Cecini, A. Palmeri, Comp. Struct., 147, 26 (2015)

[2] L.E. Suárez, L.A. Montejo, I. J. Sol. Struct., 42, 5905 (2005)

[3] D. Sun, Q. Ren, Shock Vib., 2016, 1 (2016)

[4] M. Ćosić, R. Folić, B. Folić, Građ., 66, 787 (2014)

[5] G. Barone, F. Lo Iacono, G. Navarra, A. Palmieri, $1^{\text {st }}$ ECCOMAS Thematic Conference on Uncertainty Quantification in Computational Sciences and Engineering, UNCECOMP 2015, 394 (2015)

[6] R. Chtcot, M.R. Brasil L.R.F., Rev. Inter. Pesq. Enge., 2, 53 (2016)

[7] Comisión Permanente de Normas Sismorresistentes (NCSR-02), Norma de Construcción Sismorresistente: parte general y edificación, Madrid, Spain (2002)

[8] A.H. Barbat, L. Orosco, J.E. Hurtado, M. Galindo, Definición de la acción sísmica (CIMNE IS-10, Barcelona, 1994)

[9] Wolfram Mathematica, Version 11 Student Edition, Wolfram Research, Inc (2017)

[10] M. Alembagheri, Soil Dyn. Earth. Eng., 90, 327 (2016)

[11] Inventory of Dams and Reservoirs (SNCZI), http://sig.mapama.es/snczi/visor.html (2017)

[12] Spanish Association of Dams and Reservoirs (SEPREM), http://www.seprem.es/index.php (2017) 